\title{
Eficiência de diferentes ramais de pulverização e volumes de calda no controle de Brevipalpus phoenicis na cultura do café
}

\author{
Ana Paula Fernandes ${ }^{1}$, Marcelo da Costa Ferreira ${ }^{1} \&$ Carlos Amadeu Leite de Oliveira $^{1}$
}

${ }^{1}$ Departamento Fitossanidade, Universidade Estadual Paulista, Campus de Jaboticabal, Rodovia Prof. Dr. Donato Castellane, s/n, 14884-900 Jaboticabal-SP, Brasil.aninha_taa@yahoo.com.br; mdcosta@fcav.unesp.br; amadeu@fcav.unesp.br

\begin{abstract}
Efficiency of different spraying lances and spraying volumes on the control of Brevipalpus phoenicis in coffee crops. The mite Brevipalpus phoenicis is found on coffee plantations in Brazil since the 1950's. Responsible for indirect losses due to its role as vector of a virus disease, this mite species often requires control measures, the most common based on mitecide spraying. It was evaluated the mortality of $B$. phoenicis due the coverage of spraying liquid applied on coffee plants, with two types of lances used in air assisted sprayers and four spraying volumes. Treatments were applied with mitecide abamectin (Vertimec 18 $\mathrm{CE}^{\circledR}$ at $0.4 \mathrm{~L}$ per hectare), in volumes of $250,400,550$ and $700 \mathrm{~L}$ per hectare, with two types of lances for the nozzles. The control efficiency against $B$. phoenicis, deposition and coverage by spray liquid on coffee plants was evaluated. Experimental delineation was in randomized blocks, with eight treatments plus a check plot in four replications. The statistical analysis was carried in a factorial scheme $2 \times 4+1$. No significant differences in the number of mites were found between treatments. As regards spraying liquid deposition, it was observed an increment with increasing spraying volumes, with the plant tops showing the best deposition of spraying liquid. The duplication of the lances (nozzle branches) resulted in a significant increase in control efficiency for $B$. phoenicis compared with conventional branch and with check plot, without dependence of spraying volume.
\end{abstract}

KEYWORDS. Chemical control; droplet size; sprayer; spraying nozzles.

RESUMO. Eficiência de diferentes ramais de pulverização e volumes de calda no controle de Brevipalpus phoenicis na cultura do café. O ácaro Brevipalpus phoenicis é encontrado nos cafezais do Brasil desde a década de 50. Responsável por perdas indiretas por ser o vetor de uma doença virótica requer constantes medidas de controle, sendo a mais utilizada baseada na pulverização de acaricidas. Avaliou-se a mortalidade do ácaro B. phoenicis em função da cobertura de calda aplicada em plantas de café, com dois tipos de ramais utilizados em pulverizadores de jato transportado e quatro volumes de aplicação. O produto utilizado para $o$ trabalho foi o acaricida abamectina (Vertimec $18 \mathrm{CE}^{\circledR}$ na dose de $0,4 \mathrm{~L} / \mathrm{ha}$ ). Os tratamentos utilizados foram a aplicação do acaricida abamectina, nos volumes de 250, 400, 550 e $700 \mathrm{~L} / \mathrm{ha}$, com dois tipos de ramais de bicos. Em cada tratamento foram avaliadas a eficiência de controle de B. phoenicis, a deposição e a cobertura da calda nas plantas de café. O delineamento experimental utilizado foi em blocos casualizados, com oito tratamentos mais uma testemunha e quatro repetições. A análise estatística foi realizada no esquema fatorial $2 \times 4+1$. Verificou-se que não houve diferenças significativas no número de ácaros encontrados entre os tratamentos. Para a deposição de calda, observou-se um aumento em função do volume de aplicação, sendo que a parte superior das plantas apresentou maior deposição de produto. A duplicação dos ramais resultou em um aumento significativo da eficiência de controle de B. phoenicis comparado ao ramal convencional e à testemunha, independe do volume de aplicação entre os limites avaliados.

PALAVRAS-CHAVE. Controle químico; diâmetro de gotas; pulverizador; pontas de pulverização.

A cultura do café (Coffea arabica L.) representa parte da história do Brasil e quando se trata de agricultura a sua importância torna-se ainda mais relevante. O Brasil, em sua vasta extensão, possui aptidão edafo-climática para a produção de café, de variadas espécies. Porém, esta mesma extensão e clima oferecem dificuldades logísticas e produtivas que, por sua vez, aumentam os custos de produção e comercialização (Parreira et al. 2005).

Além dos problemas logísticos os cafezais brasileiros são infestados por diversas pragas que por demandarem controle, aumentam os custos de produção. As pragas e doenças que ocorrem na cultura do café são de extrema importância, pois diminuem a produtividade e afetam a qualidade da bebida. Do custo total de produção de uma lavoura tradicional de café, $44,7 \%$ dos gastos são com insumos. Destes, $18,9 \%$ são destinados aos produtos fitossanitários, sendo que desse valor $54,1 \%$ é gasto com acaricidas e/ou inseticidas, refletindo sua participação no sistema produtivo (Agrianual 2009, 2008), o que implica em estudos para minimizar esses gastos e maximizar a eficiência do tratamento.

Atualmente entre as pragas de importância na cultura do café destaca-se o ácaro plano ou ácaro da mancha anular do cafeeiro Brevipalpus phoenicis (Geijskes 1939). Este ácaro tem sido relatado em cafeeiros desde a década de 1950, no entanto a partir de 1973 foi relacionado à doença denominada mancha-anular do cafeeiro (Chagas 1973) e desde então sua importância tem aumentado. Por ser de natureza virótica, a mancha-anular do cafeeiro tem preocupado os cafeeicultores. A doença causa desfolha antecipada dos cafezais infectados, alteração na coloração dos frutos e perda de qualidade da bebida do café que passa de mole para dura (Reis \& Chagas 2001). O ácaro vem causando problemas principalmente no cerrado de Minas Gerais, onde o seu controle tem sido realizado sistematicamente com uma a duas aplicações anuais de acaricidas. No entanto, o número de acaricidas registrados para o controle deste ácaro na cultura do café e os 
métodos de aplicação ainda são bastante escassos. O controle deve ser realizado em função da incidência da doença e não do número de ácaros. Caso seja constatada a incidência da mancha-anular em um cafezal, recomenda-se o controle do ácaro vetor, através de aplicações de acaricidas seletivos aos ácaros predadores (Reis 2004).

$\mathrm{Na}$ aplicação dos produtos fitossanitários, a deposição e a distribuição da calda sobre as plantas dependem de fatores como: tamanho das plantas ou densidade da copa, tamanho das gotas, volume de água, forma e volume da planta, velocidade de deslocamento do pulverizador, vento e tipo de equipamento (Byers et al. 1984). O formato do cafeeiro também pode constituir dificuldades para atingir diretamente o ácaro durante a pulverização em frutos, folhas e ramos mais internos à copa (Scudeler et al. 2004).

Segundo Reis (2000), ovos e ácaros de B. phoenicis foram encontrados no terço inferior e médio das plantas, tanto nas folhas quanto nos ramos e frutos. Nas folhas, o maior número de ovos e ácaros foi encontrado naquelas dos terços inferior e médio e posição interna da planta, ou seja, naquelas da parte proximal aos ramos, e em menor número nas folhas da parte superior e posição externa da planta ou parte distal dos ramos. Nos ramos, o maior número de ovos e ácaros foi encontrado na parte do ramo que não apresentava folhas, ou do interior da copa das plantas. Nos frutos, a maior quantidade de ácaros ocorreu naquelas do terço inferior das plantas, onde foram encontrados mais ovos do que outros estádios do ácaro. Nas folhas e ramos, em relação à altura nas plantas e posição interna e externa, verificou-se na análise da distribuição espacial que o ácaro apresentou uma distribuição agregada no cafeeiro. Nos frutos a distribuição foi regular. Visando o controle, as amostragens serão mais representativas se forem feitas em ramos e em frutos nos interiores do terço médio inferior das plantas.

De distribuição em maior população da forma descrita acima, o ácaro B. phoenicis é portanto encontrado por toda a copa das plantas. Isto requer uma pulverização realizada de forma a cobrir da melhor uniformidade possível ao cafeeiro. Atualmente, os produtores de café visam atingir este objetivo aumentando o volume de aplicação de calda o que aumenta os custos de produção. Na tentativa de melhorar a cobertura das plantas têm sido realizados trabalhos em diversas culturas de porte arbóreo, como a dos citros, onde B. phoenicis é praga de grande importância. Os trabalhos têm objetivado determinar a qual a cobertura suficiente para um bom controle da praga, propondo limites aceitáveis de volume de aplicação (Ferreira 2003). Outros autores avaliaram diferentes diâmetros de gotas na tentativa de baixar o volume de aplicação sem comprometer a cobertura no interior da copa das plantas (Ramos et al. 2007).

Por ter tamanho reduzido, corpo plano e se alojar nas partes internas às copas das plantas, o ácaro não é atingido facilmente pelas pulverizações, exigindo critérios na tecnologia de aplicação empregada para que o tratamento fitossanitário seja economicamente viável em relação ao volume de calda e ao desempenho operacional, sem comprometer a eficácia do controle (Ferreira 2000).
Desta forma, objetivou-se avaliar a eficiência de dois tipos de ramais de pulverização acoplados em pulverizadores de jato transportado e quatro volumes de calda para o controle do ácaro B. phoenicis em plantas de café.

\section{MATERIAL E MÉTODOS}

O experimento foi realizado na Fazenda Cascata, no município de Altinópolis-SP, Brasil. As aplicações foram realizadas no dia 05 de abril de 2007, em cafezal da cultivar Catuaí, com 13 anos de idade, espaçamento de 4,0 por 0,75 metros. Durante a realização das aplicações a temperatura variou entre 27 e $32{ }^{\circ} \mathrm{C}$, UR de 30 a $52 \%$ e ventos de 2 a 6,5 $\mathrm{km} / \mathrm{h}$. As plantas estavam com altura de aproximadamente dois metros. O período de duração do experimento foi de seis meses, sendo a última avaliação realizada em setembro de 2007.

O delineamento experimental utilizado foi em blocos casualizados, com oito tratamentos mais uma testemunha e quatro repetições. Os tratamentos avaliados foram: aplicação da calda acaricida nos volumes de 250, 400, 550 e $700 \mathrm{~L} /$ ha, utilizando dois tipos de ramais de pulverizador - ramal convencional e ramal duplicado - e uma testemunha mantida na ausência de controle com acaricida. No ramal convencional foram utilizados 22 bicos JA-2 (preto), cone vazio, da marca Jacto, sendo onze bicos para cada lado, estando o bico mais baixo a $0,5 \mathrm{~m}$ e o mais alto a $1,8 \mathrm{~m}$ de altura em relação ao solo. No ramal duplicado foram utilizados 44 bicos JA-1 (azul), cone vazio, da marca Jacto utilizando as mesmas características de altura mencionadas anteriormente (Figura 1).

Esses bicos foram selecionados por se caracterizarem pela produção de gotas classificadas como finas a muito finas, necessárias para atingir todas as partes da planta, inclusive os ramos internos onde B. phoenicis ocorre em maiores densidades populacionais (Reis 2000). As aplicações foram realizadas com um pulverizador tratorizado de jato transportado (Turbo Atomizador Arbus 400, Máquinas Agrícolas Jacto S. A.), montado em trator Massey Ferguson, MF 265 a $1500 \mathrm{rpm}$ e velocidade variável de acordo com o volume de calda aplicado (Tabela I).

$\mathrm{O}$ acaricida utilizado para o trabalho foi a abamectina (Vertimec 18 ( $\mathrm{CE}$ ) na dosagem de $0,4 \mathrm{~L} / \mathrm{ha}$, recomendada

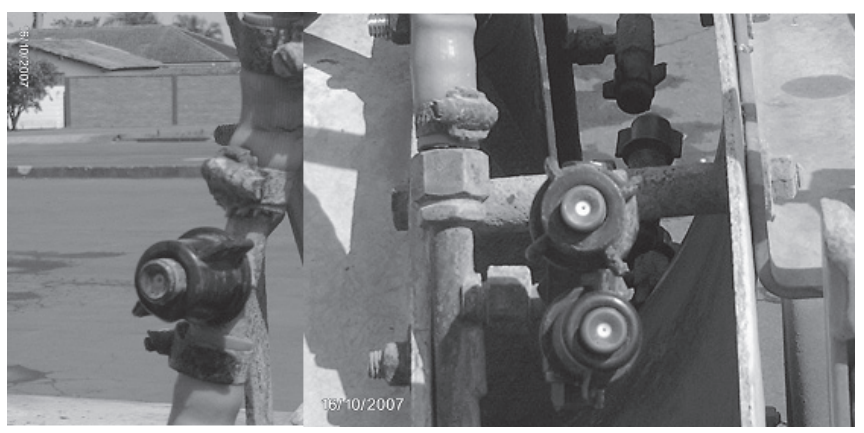

Fig. 1. Detalhe dos ramais de bicos utilizados nas aplicações dos acaricidas. (A) ramal convencional, (B) ramal duplicado. Altinópolis/SP, 2007. 
Tabela I. Condições operacionais durante a aplicação das caldas acaricidas em plantas de café. Altinópolis, São Paulo, 2007.

\begin{tabular}{cccc}
\hline Tratamentos & Pressões $\mathrm{kPa}$ & Velocidade $\mathrm{km} / \mathrm{h}$ & Marcha \\
\hline 1 & 200 & 5,4 & $1^{\mathrm{a}} \mathrm{S}$ \\
2 & 400 & 4,7 & $4^{\mathrm{a}} \mathrm{R}$ \\
3 & 780 & 4,7 & $4^{\mathrm{a}} \mathrm{R}$ \\
4 & 700 & 1,0 & $3^{\mathrm{a}} \mathrm{R}$ \\
5 & 200 & 5,4 & $1^{\mathrm{a}} \mathrm{S}$ \\
6 & 400 & 4,7 & $4^{\mathrm{a}} \mathrm{R}$ \\
7 & 450 & 1,0 & $3^{\mathrm{a}} \mathrm{R}$ \\
8 & 220 & 2,0 & $2^{\mathrm{a}} \mathrm{R}$ \\
\hline
\end{tabular}

para a cultura do café. Este acaricida foi escolhido devido a apresentar baixa toxicidadade (classe toxicológica IIImedianamente tóxico) e mostrar-se eficiente para o controle de B. phoenicis com base em experimento prévio realizado em condições laboratoriais com ácaros provenientes de citros e cafezais, sem uso recente de acaricidas (Fernandes et al. 2008).

Cada parcela foi constituída por 180 plantas, distribuídas em três linhas paralelas e consecutivas de 60 plantas cada, sendo que uma das linhas na margem de cada parcela foi mantida como bordadura, sem aplicação de acaricida.

Para estimar a eficiência de controle dos tratamentos foram realizadas avaliações da densidade populacional de $B$. phoenicis um dia antes da aplicação dos tratamentos (0 DAA) e aos 10, 30, 60, 90, 120 e 150 dias após a aplicação. Foram avaliadas dez plantas da linha central da parcela. Sendo que em cada planta foi retirado um ramo de $20 \mathrm{~cm}$ localizado no terço médio inferior e interno seguindo metodologia proposta por Reis et al. (2000). Em seguida, os ramos foram acondicionados em sacos de papel para o transporte até o laboratório de Acarologia do Departamento de Fitossanidade da UNESP, Câmpus de Jaboticabal.

No laboratório, as folhas foram destacadas dos ramos, totalizando 10 ramos e vinte folhas por parcela para serem submetidas à "máquina de varredura" para coleta de ácaros (Oliveira 1983). Utilizando um microscópio estereoscópico foi realizada a contagem de $B$. phoenicis vivos encontrados no material. A contagem foi realizada em uma faixa de 11 $\mathrm{cm}^{2}$, delimitada na placa de vidro da máquina de varredura. De posse dos dados de densidade populacional foi calculada a eficiência de controle utilizando a fórmula de Henderson $\&$ Tilton (1955), em que se estimou o efeito do acaricida (equação 1).

$$
\mathrm{E}=100 \times\left(1-\frac{T a \times C b}{T b \times C a}\right) \text { (1); em que: }
$$

E: Efeito do acaricida (\%);

Ta: número de ácaros na parcela após a aplicação;

Tb: número de ácaros na parcela antes da aplicação;

$\mathrm{Cb}$ : número de ácaros na testemunha antes da aplicação;

Ca: número de ácaros na testemunha após a aplicação.

Para avaliar a deposição de calda na superfície foi adicionada como marcador às caldas acaricidas uma concentração de $150 \mathrm{~g}$ de Cuprogarb $500^{\circledR}$ (equivalente a
$840 \mathrm{~g}$ de oxicloreto de cobre ou $500 \mathrm{~g}$ do cátion metálico $\mathrm{Cu}^{+2} / \mathrm{kg}$ produto comercial), para cada $100 \mathrm{~L}$ de água. $\mathrm{O}$ fungicida cúprico foi escolhido como marcador por ser da classe toxicológica IV (pouco tóxico) e não sofrer perdas significativas na concentração desde a coleta até a quantificação em laboratório (Machado Neto \& Matuo 1989), além de ser um produto registrado para a cafeicultura.

Após a secagem das caldas sobre as plantas de café, foram coletadas quatro folhas em oito pontos de amostragem, sendo estes pontos localizados nos terço baixo e alto dos quatro lados da planta central da parcela (Figura 2).

Para a avaliação da deposição, somente foram utilizadas as folhas do cafeeiro. Isto está de acordo com Ramos et al. (2007), que relatam que a utilização de ramos deve ser evitada em função da maior retenção de calda por essa estrutura, o que dificulta evidenciar os efeitos entre tratamentos. Foi coletada uma amostra da calda aplicada e as folhas retiradas dos terços baixo e alto da planta foram acondicionadas em sacos plásticos distintos e levadas ao laboratório para solubilização do íon $\mathrm{Cu}^{+2}$ com $\mathrm{HCl} 0,1 \mathrm{~N}$, por 2 horas. Após a extração do cobre das folhas, o extrato foi analisado em espectrofotômetro de absorção atômica para a quantificação do íon metálico no extrato e posteriores cálculos de deposição.

Para o cálculo da deposição, foi necessária a quantificação da área foliar. Para tanto, as folhas de café foram em seguida lavadas e secas, sendo posteriormente escaneadas. As imagens obtidas foram analisadas através do software QUANT v.1.0.0.22 para obtenção da área foliar total (Fernandes Filho et al. 2002).

Para estimar a deposição de cobre $/ \mathrm{cm}^{2}$ de área foliar, os valores de cobre, em $\mu \mathrm{g} / \mathrm{mL}$ de calda, encontrados na leitura do espectrofotômetro de absorção atômica foram multiplicados pelo volume de $100 \mathrm{~mL}$ de $\mathrm{HCl}$ utilizado nas diluições para a extração do cobre das folhas de café. De posse da quantidade de cobre em $\mu \mathrm{g}$ das quatro folhas utilizadas na extração dividiu-se o valor pela área foliar total das amostras.

A cobertura de calda na superfície foliar foi avaliada com o uso de papéis sensíveis distribuídos em oito pontos da copa de cada arvore, utilizando os mesmos critérios adotados para a avaliação da deposição, sendo a coleta realizada após a secagem das folhas. Em seguida os papéis foram levados ao

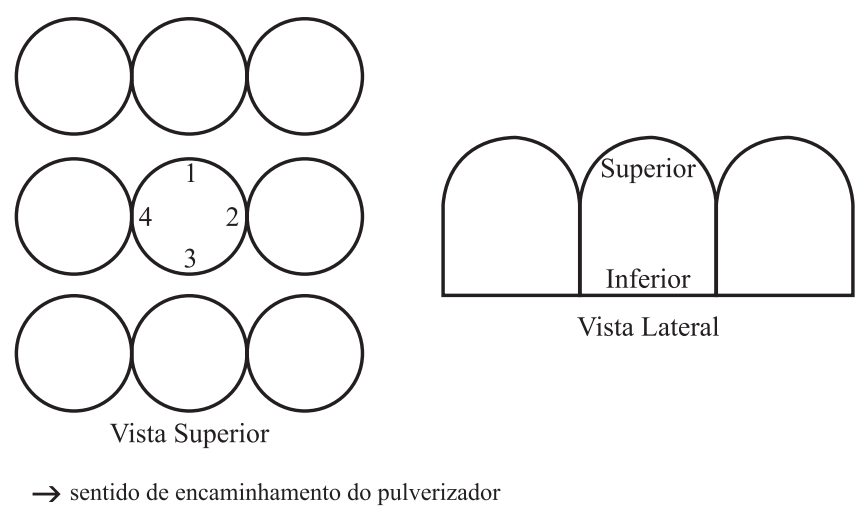

Fig. 2. Esquema da distribuição dos pontos de coleta de folhas para avaliação da deposição da calda sobre as plantas de café. Altinópolis/SP, 2007. 
Laboratório de Análise do Tamanho de Partículas - LAPAR do Departamento de Fitossanidade da UNESP de Jaboticabal, para análise de imagem pelo software QUANT v.1.0.0.22 (Fernandes Filho et al. 2002).

A eficiência dos tratamentos, a deposição de resíduos e a cobertura sobre as folhas, foram analisadas no esquema fatorial 2x4+1 (2 ramais de bicos, 4 volumes de aplicação e uma testemunha), em quatro repetições. Portanto, cada tratamento constou de 720 plantas. O nível de significância adotado foi de $\alpha=0,05$.

\section{RESULTADOS E DISCUSSÃO}

$\mathrm{Na}$ análise prévia da densidade populacional de ácaros (0 DAA), realizada na área experimental, verificou-se que não havia diferenças significativas no número de ácaros encontrados entre os tratamentos, refletindo uma uniformidade aceitável para o uso do delineamento estatístico adotado. $\mathrm{O}$ número de ácaros na área estava entre 1,5 e 3 ácaros por planta amostrada (folhas + ramos) (Tabela II). Esta baixa população de ácaros manteve-se nas avaliações realizadas durante o experimento (Figura 3) e pode ter sido devido às chuvas, que ocorreram no decorrer do experimento, uma vez que o índice pluviométrico, nos três dias seguintes à aplicação do acaricida, foi de 16, 64 e $14 \mathrm{~mm}$ de precipitação e de $31 \mathrm{~mm}$ em 21 de abril, $58 \mathrm{~mm}$ em 23 de maio e $30 \mathrm{~mm}$ em 24 de junho. Esses valores pluviométricos em um único dia, dependendo do período de chuva, podem acarretar na diminuição da população de ácaros das plantas de café.

Em trabalhos desenvolvidos por Oliveira (1986) de 1979 a 1983, nos municípios de Jaboticabal, Taiúva, Bebedouro e Guaraci no estado de São Paulo, em pomares de laranja da variedade Pera, utilizando-se áreas isentas de tratamento com produtos fitossanitários, constataram-se as mais altas infestações do ácaro B. phoenicis nos anos de 1980 e 1981. A causa provável destas infestações seriam as temperaturas amenas e os longos períodos de estiagens. Nos anos de 1982 e 1983, observados em idênticos períodos, foram encontrados níveis populacionais mais baixos. O ácaro ocorre com maior frequência no inverno, quando a precipitação pluvial é menor, condição verificada como mais favorável ao seu desenvolvimento populacional.

Tabela II. Média do número de ácaros vivos em plantas de café em análise prévia realizada um dia antes da pulverização de caldas acaricidas. Altinópolis, São Paulo, 2007

\begin{tabular}{cccc}
\hline \multirow{2}{*}{ Tratamentos } & \multicolumn{3}{c}{ Média $^{1}$ do número de ácaros vivos } \\
\cline { 2 - 4 } & Folhas & Ramos & Folhas + Ramos \\
\hline 1 & $1,78 \mathrm{a}$ & $1,40 \mathrm{a}$ & $2,05 \mathrm{a}$ \\
2 & $1,10 \mathrm{a}$ & $1,57 \mathrm{a}$ & $1,67 \mathrm{a}$ \\
3 & $1,47 \mathrm{a}$ & $1,72 \mathrm{a}$ & $2,10 \mathrm{a}$ \\
4 & $1,62 \mathrm{a}$ & $1,98 \mathrm{a}$ & $2,38 \mathrm{a}$ \\
5 & $1,35 \mathrm{a}$ & $1,46 \mathrm{a}$ & $1,74 \mathrm{a}$ \\
6 & $1,47 \mathrm{a}$ & $1,64 \mathrm{a}$ & $1,99 \mathrm{a}$ \\
7 & $1,67 \mathrm{a}$ & $2,42 \mathrm{a}$ & $2,80 \mathrm{a}$ \\
8 & $1,60 \mathrm{a}$ & $1,52 \mathrm{a}$ & $1,93 \mathrm{a}$ \\
Testemunha & $1,40 \mathrm{a}$ & $1,80 \mathrm{a}$ & $2,05 \mathrm{a}$
\end{tabular}

${ }^{1}$ Médias seguidas de mesma letra não diferem entre si, pelo teste de Tukey $(\mathrm{P}<0,05) .{ }^{2}$ Dados transformados em $\sqrt{x+1}$.

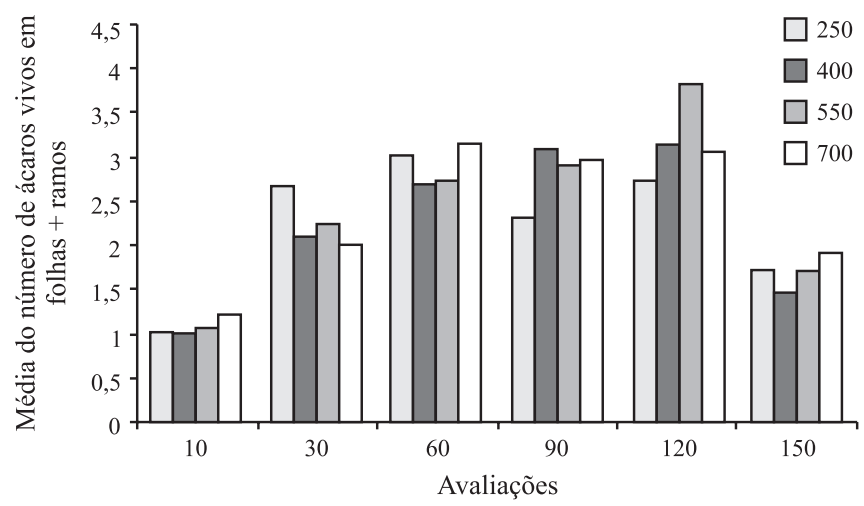

Fig. 3. Média do número de ácaros vivos em folhas e ramos de café ao longo do tempo para diferentes volumes de aplicação estudados. Altinópolis/SP, 2007.

As chuvas verificadas na área também podem ter diminuído o período de controle pelo acaricida, embora tenha ocorrido uma diminuição da população de ácaros 10 dias após a aplicação, para todos os tratamentos estudados na média dos dois equipamentos e para os quatro volumes avaliados (Figura 3). Nas avaliações realizadas a partir dos 30 dias houve um aumento da densidade populacional de ácaros. No entanto, não foi verificada uma média superior a quatro ácaros por série de órgãos avaliados (ramos + folhas), não apresentando diferença significativa entre os tratamentos (Figura 3).

Para os resultados de deposição, observa-se um aumento em função do volume de aplicação. $\mathrm{O}$ aumento da deposição foi diretamente proporcional ao aumento do volume de aplicação com melhor correlação para o ramal simples na posição mais baixa da planta e para o duplicado na posição alta da planta (Tabela III). De maneira geral, houve uma melhor correlação do aumento do volume em relação à deposição para o ramal simples, como pode ser observado nos valores de $\mathrm{R}^{2}$.

Os valores observados para o ramal convencional foram maiores do que para o ramal duplo, exceto com o volume de aplicação de $400 \mathrm{~L} /$ ha em que houve maior deposição para o ramal duplicado (Figura 4).

Em relação à altura, observa-se uma maior deposição na parte superior em relação a parte inferior das plantas de café, sendo que o ramal convencional apresentou as maiores diferenças de deposição entre as duas alturas estudadas, sendo a condição ideal é a distribuição uniforme por toda a copa da planta. Isto pode ter ocorrido em função do maior diâmetro das gotas, menos suscetíveis à deriva em relação

Tabela III. Equação de regressão linear e coeficiente de correlação da deposição em relação aos volumes de aplicação de acaricidas sobre as plantas de café. Altinópolis/SP, 2007.

\begin{tabular}{ccc}
\hline Ramal/Posição & Equação & R2 \\
\hline Simples/alto & $\mathrm{y}=0,0079 \mathrm{x}+0,452$ & 0,5736 \\
Simples/baixo & $\mathrm{y}=0,0031 \mathrm{x}+1,189$ & 0,824 \\
Duplicado/alto & $\mathrm{y}=0,0045 \mathrm{x}+1,2663$ & 0,7555 \\
Duplicado/baixo & $\mathrm{y}=0,002 \mathrm{x}+1,8668$ & 0,1169 \\
\hline
\end{tabular}




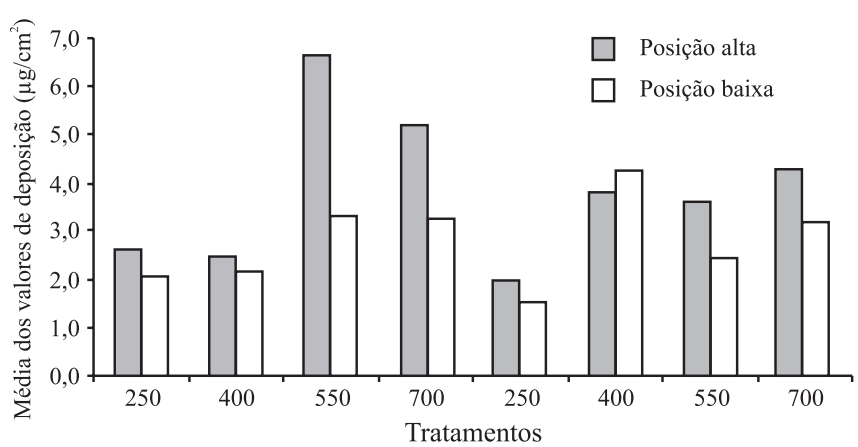

Ramal simples

Ramal duplo

Fig. 4. Média dos valores de deposição de calda, em $\mu \mathrm{g} / \mathrm{cm}^{2}$ de cobre, em função da posição amostrada nas plantas de café. Altinópolis/SP, 2007.

ao ramal duplicado. Esses resultados diferem dos observados por Ramos et al. (2007) para a deposição de calda em plantas de citros, que constataram menores coberturas e deposições obtidas no meio e no ponteiro das plantas de citros.

Entretanto, essa diferença em relação à posição que recebeu o maior depósito de calda entre as plantas de citros e de café ocorreu provavelmente devido à altura das plantas e ao posicionamento do pulverizador. Plantas de citros são geralmente mais altas que plantas de café, portanto, o depósito de calda nas plantas de citros seria maior na parte inferior. Isso ocorre devido à dificuldade em se atingir a parte superior das plantas de citros uma vez que os pulverizadores são, em geral, bem mais baixos que as plantas e a pulverização acaba ocorrendo de maneira tangencial à copa das árvores (Matuo 1988). Já para as plantas de café verificadas na área experimental, a altura estava compatível com a altura do pulverizador que contava ainda com extensores na barra, o que possibilitou uma boa deposição também no topo da copa dos cafeeiros. Hall et al. (1981), estudando o efeito do volume de aplicação na deposição, em pomares de macieira, verificaram que as aplicações em ambos os volumes, $301 \mathrm{e}$ $718 \mathrm{~L} / \mathrm{ha}$, produziram significativamente maior deposição na média total que no volume de 167 L/ha. A aplicação no volume de $301 \mathrm{~L} /$ ha apresentou maior deposição do que a $167 \mathrm{~L} / \mathrm{ha}$, em todas as alturas da planta, exceto no topo, a 4,6 m. Na comparação com $718 \mathrm{~L} /$ ha, o volume de $301 \mathrm{~L} /$ ha, apresentou maior deposição total, embora, sem diferenças estatisticamente significativas.

Embora os tratamentos com 550 e $700 \mathrm{~L} / \mathrm{ha}$, com o ramal convencional tenham apresentado maiores valores de cobertura (Figura 5), não houve relação entre essa cobertura e a eficiência no controle dos ácaros. Para o ramal duplo, tanto para cobertura quanto para volume não houve relação com a eficiência no controle do ácaro.

Scudeler et al. (2004) avaliaram e compararam a distribuição e o depósito de uma solução marcadora, bem como a eficiência do regulador de crescimento ethephon na maturação dos frutos do cafeeiro, quando aplicados com diferentes pulverizadores e condições operacionais. Observaram que a maior cobertura foi obtida na pulverização com o equipamento Arbus 400, pontas JA-2 a $621 \mathrm{kPa}$, na

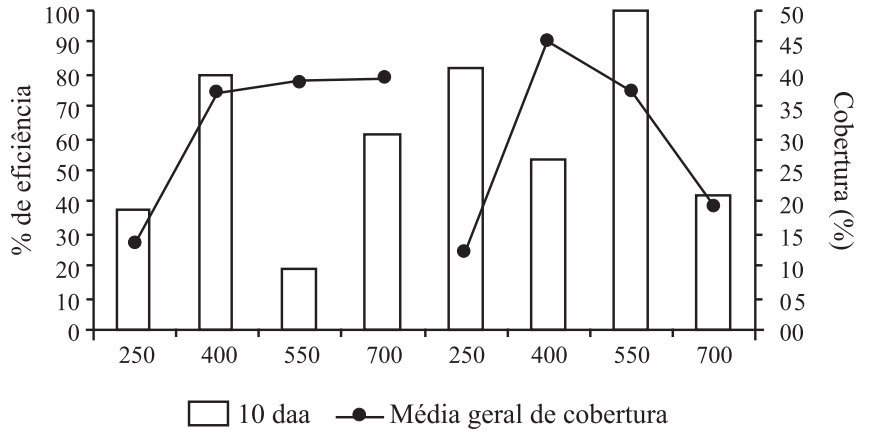

Ramal simples

Ramal duplo

Fig. 5. Relação entre a porcentagem de eficiência dos tratamentos aos 10 dias após a aplicação (daa) das caldas acaricidas e a média geral dos valores de cobertura observados nos tratamentos. Altinópolis/SP, 2007.

parte inferior da planta, mesmo não sendo esse o tratamento com maior volume de calda. Os tratamentos utilizando o equipamento Arbus 400, com pontas JA-2 a $621 \mathrm{kPa}$ e pontas JA-2 a $1035 \mathrm{kPa}$, resultaram em maior cobertura na posição inferior de amostragem em relação aos demais.

$\mathrm{O}$ volume de $400 \mathrm{~L} /$ ha proporcionou eficiência do ramal duplicado 1,4 vezes superior ao ramal convencional. Em relação à eficiência dos tratamentos (Figura 5), observa-se valores acima de $80 \%$ para os tratamentos com volumes de aplicação de $400 \mathrm{~L} / \mathrm{ha}$ (ramal convencional) e 250 e $550 \mathrm{~L} / \mathrm{ha}$ (ramal duplicado). No tratamento com o volume de aplicação de $550 \mathrm{~L} /$ ha e ramal duplicado observa-se uma eficiência de $100 \%$. A média de eficiência para o ramal duplicado foi maior $(70 \%)$ que a do ramal convencional (50\%). Como já correlacionado anteriormente, o aumento no volume de aplicação significou maior deposição, principalmente para o ramal convencional (Figura 4). Avaliando estes resultados com a eficiência de controle, não há uma correlação direta, uma vez que na maior deposição do ramal duplicado que ocorreu com o volume de aplicação de 400 L/ha, verificou-se uma eficiência de controle de $60 \%$, enquanto para a deposição menor $(250 \mathrm{~L} / \mathrm{ha})$ a eficiência foi de cerca de $80 \%$. A maior eficiência média para o ramal duplicado pode ser justificada pela melhor uniformidade de deposição da calda na copa das plantas (Figura 3). O desvio padrão médio da deposição para o ramal convencional $(1,33)$ foi cerca de $30 \%$ superior ao do ramal duplicado $(1,06)$. Isto pode ser verificado na análise estatística, onde não houve diferenças significativas entre os volumes de aplicação relacionados aos números de ácaros na área tratada. Os resultados das análises estatísticas não foram apresentados, em função de não apresentarem diferenças significativas, ao nível de 5\% de probabilidade.

Apesar dos volumes de $250 \mathrm{~L} /$ ha aos 30 dias e $550 \mathrm{~L} /$ ha aos 120 dias após as aplicações terem se destacado em relação ao número de ácaros encontrados nas plantas de café, não se pode dizer que há vantagem para qualquer dos volumes utilizados, evidenciando que qualquer um destes volumes podem ser empregados no cafeeiro para o controle de B. phoenicis. 


\section{CONCLUSÃO}

Conclui-se que a eficiência de controle é maior com a duplicação do ramal de bicos do pulverizador e o controle independe do volume de aplicação entre os limites avaliados neste trabalho.

Agradecimentos. Aos proprietários da Fazenda Cascata, município de Altinópolis - SP, por cederem a área ao trabalho e aos seus funcionários por colaborarem na instalação dos experimentos e a CAPES - Coordenação de Aperfeiçoamento de Pessoal de Nível Superior, pela bolsa de estudos concedida ao primeiro autor, externamos sinceros agradecimentos.

\section{REFERÊNCIAS}

Agrianual 2009: Anuário da agricultura brasileira. 2008. São Paulo: FNP Consultoria \& Comércio, p. 225.

Agrofit. Disponível em: <http:/extranet.agricultura.gov.br/dev60cgi/ rwcgi60? agrofit_cons\&ingredientes_ativos.rdf\&p_id_i $>$. Acesso em 15 de setembro de 2007 .

Alm, S. R.; D. L. Reichard \& F. R. Hall. 1987. Effects of spray drop size and distribution of drops containing bifenthrin on Tetranychus urticae (Acari: Tetranychidae). Journal of Economic Entomology 80: 517-20.

Byers, R. E.; C. G. Lyons Jr.; K. S. Yoder; R. L. Horsburgh; J. A. Barden \& S. J. Donohue. 1984. Effects of apple tree size and canopy density on spray chemical deposit. HortScience 19: 93-4.

Chagas, C. M. 1973. Associação do ácaro Brevipalpus phoenicis (Geijskes) à mancha-anular do cafeeiro. O Biológico 39: 229-232.

Fernandes, A. P.; M. C. Ferreira \& N. M. Martinelli. 2005. Mortalidade do ácaro Brevipalpus phoenicis em função da cobertura de pulverização de acaricidas, com e sem adjuvantes, em mudas de café. Revista de Agricultura 80: 173-187.

Fernandes, A. P.; C. A. L. Oliveira \& M. C. Ferreira. 2008. Eficiência de acaricidas sobre populações de Brevipalpus phoenicis (Geijskes) (Acari: Tenuipalpidae) de citros e cafeeiro. Revista de Agricultura 83: 47-55.

Fernandes Filho, E. I.; F. X. R. Vale; L. Zambolim \& J. R. Liberato. 2002. Software QUANT v.1.0.0.22 - Quantificação de Doenças de Plantas. Universidade Federal de Viçosa, CD-ROM.
Ferreira, M. C. 2000. Validação do modelo matemático na avaliação da capacidade operacional de turboatomizadores em citros. Dissertação (Mestrado em Produção Vegetal) - Faculdade de Ciências Agrárias e Veterinárias, Universidade Estadual Paulista, Jaboticabal. 69 p.

Hall, F. R.; D. L. Reichard \& H. R. Krueger. 1981. Effects of spray volume and nozzle pressure on orchard spray deposits. Journal of Economic Entomology 74: 461-465.

Henderson, C. F. \& E. W. Tilton. 1995. Test with acaricides against the brown wheat mite. Journal of Economic Entomology 43: 157-61.

Machado Neto, J. G. \& T. Matuo. 1989. Avaliação de um amostrador para estudo da exposição dérmica de aplicadores de defensivos agrícolas. Ciência Agronômica Jaboticabal 4: 21-22.

Matuo, T. 1988. Desenvolvimento de um pulverizador intermitente operado fotoeletricamente para tratamento de pomares de citros. Tese (Livre docente) - Faculdade de Ciências Agrárias e Veterinárias, Universidade Estadual Paulista. Jaboticabal. 167 p.

Oliveira, C. A. L. 1983. Máquina de varredura de ácaro "Modelo Jaboticabal". Anais da Sociedade Entomológica do Brasil 12: 299-303.

Oliveira, C. A. L. 1986. Flutuação populacional e medida de controle do ácaro Brevipalpus phoenicis. Laranja 7: 1-31.

Parreira, R. S.; M.C. Ferreira; N. M. Martinelli \& D. H. B. Maccagnan. 2005. Influência de inseticidas utilizados no controle do bicho-mineiro do café sobre a população de ácaros fitófagos. Revista de Agricultura 80: $372-387$.

Ramos, H. H.; K. Yanai; I. M. Corrêa; R. B. Bassanezi \& L. C. Garcia. 2007. Características da pulverização em citros em função do volume de calda aplicado com turbopulverizador. Engenharia Agrícola 27: 56-65.

Reis, P. R. 2000. Onde está o ácaro? Cultivar: Grandes culturas, Pelotas, 6: $18-20$.

Reis, P. R. 2004. Anéis do prejuízo. Cultivar: Grandes culturas, Pelotas, 6: $8-10$.

Reis, P. R. \& S. J. de R. Chagas. 2001. Relação entre o ataque do ácaro-plano e da mancha-anular com indicadores da qualidade do café. Ciência e Agrotecnologia 25: 72-76.

Reis, P. R.; J. C. Souza; E. O. Sousa \& A. V. Teodoro. 2000. Spatial distribution of Brevipalpus phoenicis (Geijskes) (Acari:Tenuipalpidae) in coffee plants (Coffea arabicaL.). Anais da Sociedade Entomológica do Brasil 29: 177-183.

Scudeler, F.; C. G. Raetano; D. Araújo \& F. C. Bauer. 2004. Cobertura da pulverização e maturação de frutos do cafeeiro com ethephon em diferentes condições operacionais. Bragantia 63: 129-139. 